\title{
Diagnosis and management costs of suspicious skin lesions from a population-based melanoma screening program.
}

Louisa Gordon, $\mathrm{PhD}^{1,2}$ Health Economist, Philippa H. Youl, $\mathrm{MPH}^{1}$ Senior Research Officer, Mark Elwood, $\mathrm{MD}^{3}$ Director, Monika Janda, $\mathrm{PhD}^{1,2}$ Research Fellow, Ian $\mathrm{T}$. Ring, $\mathrm{PhD}^{4}$ Principal Medical Epidemiologist, John B. Lowe PhD 5 Professor, Joanne F. Aitken, $\mathrm{PhD}^{1,6}$ Director

\section{Affiliation of authors:}

1. Viertel Centre for Research in Cancer Control, Queensland Cancer Fund, Brisbane, Australia

2. Institute of Health and Biomedical Innovation, School of Public Health, Queensland University of Technology, Brisbane, Australia

3. National Cancer Control Initiative, Carlton, Victoria, Australia.

4. Centre for Health Services Development, University of Wollongong, Wollongong

5. Department of Community and Behavioral Health, College of Public Health, University of Iowa, Iowa City, Iowa, USA.

6. School of Population Health, University of Queensland, Brisbane, Australia

Correspondence to: Louisa Gordon, Queensland Institute of Medical Research, PO Royal Brisbane, Herston QLD.4029, Brisbane, AUSTRALIA Phone: 61-7-3845 3542 Fax: 61-7-3845 3503

Email: Louisa.Gordon@qimr.edu.au

Running head: Costs of skin cancer diagnosis and management 


\begin{abstract}
Background: Recently, massive increases in health care costs for the diagnosis and management of skin lesions have been observed (2000-2005). The aim of this study was to describe the health system costs attributed to the diagnosis and management of suspicious skin lesions detected during a trial of a population melanoma screening program (1998-2001) Setting: Queensland, Australia. Methods: Data from the trial and Medicare Australia were used to categorise and cost all suspicious skin lesions arising from the trial included general practitioner consultations, diagnosis/management and pathology. Comparisons were made with other screened and unscreened populations. Results: Overall, 2,982 lesions were treated within the trial producing a mean cost of A $\$ 118$ per lesion. Excisions for benign lesions contributed the greatest proportion of total costs (45\%). The total cost burden was approximately $10 \%$ higher for males than females, and $63 \%$ of overall costs were for persons aged $\geq 50$ years. For diagnosis and management procedures, the estimated average cost per 1000 individuals was $\$ A 23,560$ for men $\geq 50$ years from the skin cancer screening trial, compared to \$A26,967 for BreastScreen Australia and \$A3,042 for the National Cervical Screening Program. Conclusions: The proportion of costs for benign skin lesions and biopsies arising from the screening program were no higher than in the two-year period outside the trial. Diagnostic and management costs for skin cancer as a result of screening is comparable to those for breast and cervical cancer, if screening is targeted at men $\geq 50$ years.
\end{abstract}




\section{Introduction}

Skin cancer continues to be a major public health issue in countries with fair-skinned populations. In Australia in 2001, 8,885 new cases of melanoma were diagnosed among a population of approximately 19 million.(1) Those residing in the state of Queensland carry the world's highest risk for melanoma with an estimated life time risk of 1 in 17 for men and 1 in 25 for women.(2) Between 1993-2003, the incidence of melanoma in the United Kingdom grew rapidly by $42 \%$ and $27 \%$ for men and women, respectively leading to 8,000 new cases diagnosed in 2002.(3) In addition, over 374,000 people in Australia (4) and over 65,000 people in the United Kingdom were treated for nonmelanoma skin cancer (NMSC) in 2002.(3) Primarily due to this very high incidence (rather than the high cost per treatment) NMSCs were the most expensive cancer to the Australian health system in 2000-01 and represent a substantial economic burden.(4) Treatment expenditure from 1993-94 to 2000-01 increased in real terms by $24 \%$ and $56 \%$ for NMSCs and melanoma, respectively.(4)

At present skin cancers are diagnosed outside a formal screening program. In both the UK and Australia, GPs remain at the front line in the diagnosis and management of suspicious skin lesions. With respect to skin cancer, Medicare claims data over the last 10 years have shown substantial increases in the numbers of services for diagnosis, management and pathology of skin lesions (5) and their associated costs. Unlike the pigmented lesion clinics in the UK which require referral from a GP, in Australia, and especially Queensland, there has been a rapid expansion during the last five years of open-access GP-operated skin clinics. The contribution of these clinics, to informal skin screening activity in Queensland has risen significantly between 1999 and 2003. Recommendations from leading national health authorities in the UK and 
Australia do not support mass population screening for melanoma or other skin cancers (6), as conclusive evidence from randomised trials on the effectiveness of population screening in reducing mortality from melanoma is unavailable. However, there is indication from a large case-control study that melanomas detected during a deliberate skin examination (by a doctor or a lay-person) are thinner compared to those detected incidentally.(7)

Three exploratory economic analyses have modelled estimates of the cost per life year saved from melanoma screening and concluded screening could be an efficient use of health resources if targeted at men over 50 years $(8-10)$. These studies relied heavily on hypothetical cohorts and simulation modelling around assumed parameter values. This is due to the link between screening and decreased detection of thicker lesions (and subsequent reductions in mortality) remains to be established. This link is an essential prerequisite for the 'effectiveness' side of a strong cost-effectiveness analysis. For this reason, we have chosen to examine the immediate cost impact to the health system based on confirmed diagnostic and treatment pathways in our cohort and not an extensive cost-effectiveness analysis.

A large-scale cluster randomised controlled trial of population screening for melanoma began in 1998, in Queensland, Australia. The key aim of the trial was to determine the effectiveness of a community-based screening program in reducing mortality from melanoma. During the trial, 18 rural and regional communities were recruited with nine communities randomised each in the control and intervention arms (aggregate population 63,000 adults $\geq 30$ years). In the absence of sufficient numbers of thick melanomas during the trial, we could not conduct a full economic evaluation 
of this screening program (e.g., cost-effectiveness, cost-benefit analysis). However, we were in the position to establish the costs to the Australian public health care system of skin cancer management within, compared to outside, this designated screening program. This paper specifically aims to: 1) describe the costs to the health system for diagnosis, management and pathology of suspicious skin lesions detected during a screening trial; and 2) compare the proportion of costs generated for suspicious skin lesion management through the screening trial compared to all persons residing in the trial communities. We expected higher absolute and proportional costs for treatment of benign skin lesions as part of a concentrated screening effort.

\section{Methods}

The intervention, called SkinWatch, was designed to promote whole-body skin selfexamination and whole-body skin examination by a general practitioner (GP) (referred to here as clinical skin examination) (11). The SkinWatch intervention comprised a community education and awareness program, an education program for local GPs to improve their diagnostic and treatment skills and the provision of free, open-access skin screening clinics.(12) Clinics were conducted in workplaces and local community venues. Clinics were promoted in local newspapers, and in addition, random samples of men and women in each community were sent letters inviting them to attend the clinics. The clinics were staffed by both medical practitioners from within the community in addition to hiring medical practitioners from outside. Unlike pigmented lesion clinics in the UK where referral is required by a GP, doctors working within SkinWatch clinics did not treat any suspicious skin lesions (and no consultation costs were assigned to this screening examination in the subsequent analysis) but rather referred the patient back to their GP for diagnosis and 
management. The research team retained copies of all referrals. Patients who did not fill their referrals within two months were reminded by telephone or mailing and another reminder was issued five months after the referral was recived. Upon visit by their own GP, the GPs used the SkinWatch clinic referral forms for record keeping (age and sex of patient, location, clinical diagnosis and subsequent management of suspicious skin lesions) and attached histopathology reports for any excised or biopsied lesions and patient surveys (demographic information, history of skin screening behaviours and skin cancer risk factors). Sociodemographic profiles of the attendees of the SkinWatch clinics were similar to those of the communities however twice as many clinic attendees were aged 50-69 years. Further details of the project design, methods, tools and scope have been described previously. $(11,12)$

\section{Costing Analysis}

We took a health provider perspective and used patient-level clinical data to focus on the diagnosis and management costs of skin lesions. We assessed whether the randomised trial of population melanoma screening was associated with increased benign skin lesion activity, and subsequent costs. Data on the management, histopathologic diagnosis, and site of each lesion referred from the SkinWatch clinics within the intervention communities were collated for the costing analysis. Medicare is Australia's national health insurance scheme provided by the Commonwealth Government to all Australian residents of any age. It provides free or subsidised treatment by GPs for many medical services including attendances, procedures and pathology services. The Medicare Benefit Schedule (MBS) was used to categorise and assign a cost to each lesion in this analysis.(13) The size of the lesion was also required before a cost could be assigned however these data were not collected in the

Comment [LG1]: Is this statement correct Pip. Do you have a reference for it.

Comment [P2]: Louisa, we could use ref \# 17 alternatively the figures came from the ABS $\&$ I have put the ref for that at the end of the ref list. 
trial. Therefore, this information was imputed by using national MBS Item Reports.(5) MBS items for management of lesions according to size were summarised for 1995-1999 (1,348,000 claims) and proportions of each size category generated (i.e., $\leq 10 \mathrm{~mm}, 11-20 \mathrm{~mm},>20 \mathrm{~mm}$ ). The same proportions were then randomly assigned to the sample of referred lesions in this project. For lesions that were treated by cryotherapy, the clinical diagnosis was used because no pathology diagnosis was recorded. Together these lesion data enabled a MBS item number and corresponding cost to be assigned to each referred lesion. A total of 33 items were possible for skin lesion treatment and included lesion type (melanoma, SCC or BCC, benign lesion, etc.), management path (cryotherapy, excision, biopsy, etc.), lesion size and site. As a result of the initial referral, MBS items were also assigned for a standard GP consultation (for all persons who went to their GP after a SkinWatch referral), any resulting pathology services for skin lesion work-up and referrals to specialists. Data on the use of further primary cancer treatment services (e.g., radiation, chemotherapy etc), patient out-of-pocket expenses or private practitioner expenses were not collected within the trial and not included in this analysis.

Costs are reported in 2004 Australian dollars and are based on Medicare unit costs. The current comparative price level based on OECD purchasing power parities is $£ 1=$ \$AU 0.92.(14) As it was possible to have more than one lesion per patient, the means, medians and total costs were generated and summarised per lesion and per patient where appropriate. Results were produced for costs by broad cost type (i.e., GP consultation, diagnosis/management, and histopathology), broad lesion management type (i.e., melanoma excisions, SCC/BCC excisions, benign lesion excisions, biopsies, 'other treatments' and referral to specialist), gender and age. 
'Other treatments' included cryotherapy, topical creams, shave excisions, laser phototherapy, curettage and ablation techniques.

For comparison, additional Medicare data were obtained on the same MBS items for the entire population within the intervention and control communities of the trial, identified by postcode, during 2001 to 2002 , the closest time period to the trial for which data were available from Medicare. Medicare data captures all services performed by registered providers, from services eligible for MBS claims and for which a claim has been processed. As a source of medical care utilisation, this data is recommended above patient-supplied data in Australia(15). The analysis was undertaken using the computer program 'SPSS Version 13.0 for Windows'.(16)

\section{Results}

From 1998 to 2001, 16,383 skin examinations were conducted within the SkinWatch clinics in the intervention communities. A total of 2,302 patients (14.1\%) and 4,129 lesions were referred from the SkinWatch clinics back to their own GP. For 480 patients, no record of attendance at the doctor was received. Medical practitioner attendance records were therefore available for 1,822 patients presenting with 2,982 suspicious skin lesions. Further details on the clinical and secondary outcomes of this project are available elsewhere.(17)

A summary of health system costs of the SkinWatch clinics for the GP attendance, diagnosis, management and pathology required of the suspicious skin lesions, by broad cost type, is provided in Table 1. The mean cost per patient was A\$193 and mean cost per lesion $\mathrm{A} \$ 118$. The mean cost per lesion is lower than the median cost 
(A \$128) due to many patients requiring only a GP consultation with no further action/management required. The total health system cost for the diagnosis and treatment of the 2,982 skin lesions referred during this trial was A $\$ 352,533$. The largest component of total costs were diagnosis and management costs $A \$ 168,146$ or $48 \%$, followed by pathology services $\mathrm{A} \$ 136,557$ or $38 \%$ (Table 1 ).

Insert Table 1 here

Table 2 summarises costs by broad management group (i.e., by grouped MBS item codes as shown) and includes the standard cost of a GP consultation and any subsequent pathology services. As expected, the management strategy that incurred the greatest total cost (and number of lesions) was for benign lesion excisions A $\$ 159,684$ or $45 \%$ of total costs. This was followed by SCC/BCC excisions at A $\$ 77,257$ or $22 \%$ and other treatments (e.g., cryotherapy, topical creams, etc.) A $\$ 61,613$ or $18 \%$. Mean cost per lesion was highest for malignant melanomas due to the more complex excision(s) and pathology resources needed. Mean costs per lesion were relatively high for SCC/BCC excisions, lesions with multiple strategies and benign lesion excisions.

Insert Table 2 here

Total costs were examined by gender and age group in Table 3. More males than females were referred for suspicious skin lesions $(1,615$ vs 1,367$)$, and subsequently, overall costs for males were approximately $\mathrm{A} \$ 30,000$ or $10 \%$ higher. Sixty-three percent of total costs were incurred by men and women aged $\geq 50$ years. Mean cost 
per patient was similar for males and females, $A \$ 119$ versus $A \$ 117$, respectively. Males were treated for more lesions across all age groups compared to females and consequently higher absolute costs.

Insert Table 3 here

We compared the costs generated in the trial through SkinWatch referrals with all Medicare claims data generated for the intervention and control communities separately (2001-2002), excluding the costs of GP consultations and referrals to specialists (Table 4). A similar percentage of total cost for excised melanomas occurred in the SkinWatch clinics $(2.0 \%)$ compared to that recorded for all claims for the intervention (1.9\%) and control communities (1.4\%) during 2001-2002. The proportion of costs for excisions of SCC or BCCs were lower for the SkinWatch group (15.8\%) compared to all claims for the intervention (19.3\%) and control communities (18.8\%) and were similar for benign lesion excisions (26.0\%) compared to $(28.0 \%)$ and $(27.9 \%)$, for intervention and control communities, respectively. This was unexpected because we believed higher quantities of benign lesions would result from a screening program.

Insert Table 4 here

\section{Discussion}

The mean and median costs of diagnosis and management per lesion arising from a population screening program for melanoma were $\mathrm{A} \$ 118$ and $\mathrm{A} \$ 127$, respectively (A \$193 mean per patient). Mean costs per lesion were greatest for melanoma and 
SCC/BCC excisions, due to their more extensive and complex treatment and pathology needs. Excisions of benign skin lesions made up the greatest component of total costs $(45.3 \%)$ followed by SCC/BCC excisions $(21.9 \%)$. The total cost burden was approximately $10 \%$ higher for males than females, and $63 \%$ of overall costs were for persons aged $\geq 50$ years. Our data appear consistent with three previous economic analyses predicting greater efficiencies if screening was targeted for men over 50 since there is potential for greater cost-savings and benefits to occur in this cohort. (810)

Compared to all skin cancers managed for the intervention and control communities in a 2-year period outside the trial (2001-2002), referrals from the SkinWatch clinics resulted in a higher cost percentage of melanoma excisions, 'other treatments' and linked pathology services. Also, we found that the proportion of costs for excisions for $\mathrm{SCC} / \mathrm{BCC}$, benign lesions and biopsies were slightly lower for referrals from the SkinWatch clinics. Although these proportional differences are small, a shift which reduces or contains the huge absolute numbers (and associated total costs) for NMSCs is desirable in terms of health care expenditure.

The rate of abnormalities (defined as number of screenees with a suspected lesion requiring further tests or treatment, over all screenees) from SkinWatch was $14.1 \%$ compared to $8.9 \%$ from BreastScreen Australia (2002)(18) and $1.8 \%$ from the National Cervical Screening Program (2002)(19). For each of the three screening programs, we obtained average diagnosis/management costs from MBS unit costs per suspected cancer as well as confirmed abnormality rates and generated ratios of "cost per 1000 individuals screened'. These costs do not include all costs attributable to the 
screening programs (advertising, infrastructure etc). The estimated average cost per 1000 individuals was $A \$ 27,118$ for SkinWatch for persons $\geq 50$ years $(A \$ 23,560$ for men $\geq 50$ only), compared to A\$26,967 for BreastScreen Australia and A\$3,042 for the National Cervical Screening Program. While comparisons across screening programs are difficult, and our results do not include costs of all the activities of the SkinWatch program, it would appear that a population melanoma screening program in Australia may generate diagnostic and management costs comparable to those of BreastScreen Australia. These costs would be even lower if screening was targeted at older men only. Moreover, after diagnosis and excision procedures, and compared to other screening programs, most patients with melanoma do not require costly surgical and hospitalisation-related resources but instead are treated primarily in ambulant settings by GPs, surgeons or dermatologists.

Some limitations of our study should be noted. The community-based intervention was provided for regional and rural populations and it may not be possible to generalise findings to urban environments. This study was focused on the time of primary diagnosis and management only and excluded any subsequent management and follow-up costs for malignant lesions. However, estimated to be of greater magnitude, we have also not assessed any potential cost-savings and it is unknown whether early management of malignant cancers within the trial has lead to potential long-term savings of expensive adjuvant treatments for lesions diagnosed at a later stage. In contrast, this kind of assessment has been undertaken for breast cancer screening (20), concluding that future costs would partially offset public health investment in screening. Finally, we have not included costs attributable to the 
establishment and operation of the screening program (essentially a research project) but have instead concentrated on the immediate cost implications to the health system.

This paper has provided insights into costs associated with detection and management of suspicious skin lesions during a melanoma screening trial. There is some indication that screening for melanoma could have costs comparable to other screening efforts and does not seem to unduly increase the proportional costs associated with biopsy or excision of benign lesions compared to management in usual care. In the absence of mass melanoma screening, identifying mechanisms to reduce the increasing toll skin cancer has on the health system and increasing cost-efficiencies should be a research and policy priority. 


\section{References}

1. Australian Institute of Health and Welfare (AlHW), Australasian Association of Cancer Registries (AACR). Cancer in Australia 2001. AlHW cat. no. CAN 23. Canberra: Australian Institute of Health and Welfare; 2004 2004. Report No.: Cancer Series No. 28.

2. Queensland Cancer Registry, Queensland Cancer Fund. Cancer in Queensland Incidence and Mortality 1982 to 2003 Statistical Tables.

Brisbane: Queensland Cancer Registry, Queensland Cancer Fund; 2005 Nov 3. Cancer Research UK. UK Cancer Incidence. 2006 [cited 2006 Feb 1]; Available from: http://info.cancerresearchuk.org/cancerstats/types/melanoma/incidence/. 4. Australian Institute of Health and Welfare (AIHW). Health system expenditures on cancer and other neoplasms in Australia, 2000-01. AlHW cat. no. HWE 29. Canberra: Australian Institute of Health and Welfare; 2005 5. Medicare Australia. Medicare Benefits Schedule Item Report Statistics. [Medicare Online] 2005 [cited 2005 11th May]; Available from: Available at: http://www.medicareaustralia.gov.au/statistics/dyn mbs/forms/mbs tab4.shtm I

6. The Cancer Council Australia, Australasian College of Dermatologists. Position Statement: Screening and early detection of skin cancer. [cited 2006 01/03/06]; The Cancer Council Australia website]. Available from: http://www.cancer.org.au/content.cfm?randid=299825

7. McPherson M, Elwood M, English DR, Baade PD, Youl PH, Aitken JF. Presentation and detection of invasive melanoma in a high-risk population. Acad Dermatol. 2006;54(5):783-92.

8. Beddingfield FC. A decision analysis to estimate the effectiveness and cost-effectiveness of skin cancer screening and an analysis of the relevant epidemiology of the disease. Pittsburgh; 2002.

9. Freedberg KA, Geller AC, Miller DR, Lew RA, Koh HK. Screening for malignant melanoma: A cost-effectiveness analysis. J Am Acad Dermatol. 1999 Nov;41(5 Pt 1):738-45.

10. Girgis A, Clarke P, Burton RC, Sanson-Fisher RW. Screening for melanoma by primary health care physicians: a cost-effectiveness analysis. J Med Screen. 1996;3(1):47-53.

11. Aitken JF, Elwood JM, Lowe JB, Firman DW, Balanda KP, Ring IT. A randomised trial of population screening for melanoma. J Med Screen. 2002;9(1):33-7.

12. Lowe JB, Ball J, Lynch BM, Baldwin L, Janda M, Stanton WR, et al. Acceptability and feasibility of a community-based screening programme for melanoma in Australia. Health Promot Int. 2004 Dec;19(4):437-44.

13. Department of Health and Ageing. Medicare Benefits Schedule Book. Canberra: Commonwealth of Australia; 2004.

14. Organisation for Economic Co-operation and Development. Purchasing Power Parities. Main economic indicators 2006 [cited 2006 Oct 16];

Available from: http://www.oecd.org/std/ppp

15. Pollicino $\mathrm{C}$, Viney $\mathrm{R}$, Haas $\mathrm{M}$. Measuring health system resource use for economic evaluation: a comparison of data sources. Aust Health Rev. 2002;25(3):171-8. 
16. SPSS. SPSS 13.0 for Windows. 13.0 ed. New York: SPSS Incorporated; 2004.

17. Aitken JF, Janda M, Elwood M, Youl PH, Ring IT, Lowe JB. Clinical outcomes from skin screening clinics within a community-based melanoma screening program. J Am Acad Dermatol. 2006 Jan;54(1):105-14.

18. Australian Institute of Health and Welfare (AlHW), Australian Government Department of Health and Ageing. BreastScreen Australia Monitoring Report 2001-2002. AlHW cat. no. CAN 24. Canberra: Australian Institute of Health and Welfare; 2005 2004. Report No.: Cancer Series No. 29. 19. Australian Institute of Health and Welfare (AlHW), Australian Government Department of Health and Ageing. Cervical Screening in Australia 2001-2002. AlHW cat. no. CAN 22. Canberra: Australian Institute of Health and Welfare; 2005 2005. Report No.: Cancer Series No. 27.

20. Butler JB, Furnival CM, Hart RFG. The costs of treating breast cancer in Australia and the implications for breast cancer screening. Aust N Z J Surg. 1995;65:485-91.

Australian Bureau of Statistics. Census of Population and Housing. Selected Characteristics for Urban Centres and Localities. ABS catalogue No. 2016.3. Canberra., ACT, 
Table 1. Summary of Medicare $\operatorname{costs}^{1}$ for diagnosis and management of suspicious skin lesions referred from SkinWatch Clinics

\begin{tabular}{|c|c|c|c|c|c|c|}
\hline \multirow[b]{2}{*}{ Cost type } & \multicolumn{2}{|c|}{ Patients ( $\mathrm{n}=1,822)$} & \multicolumn{2}{|c|}{ Lesions $(\mathrm{n}=2,982)$} & \multirow[b]{2}{*}{ Total cost } & \multirow[b]{2}{*}{$\%$ Total cost } \\
\hline & Mean cost & Median cost & Mean cost & Median cost & & \\
\hline & \$Aus & \$Aus & \$Aus & $\$$ Aus & \$Aus & \\
\hline $\begin{array}{l}\text { Medical practitioner } \\
\text { consultation }^{2}\end{array}$ & 26 & 26 & 16 & 16 & 47,831 & $14 \%$ \\
\hline Diagnosis/Management ${ }^{3}$ & 92 & 69 & 56 & 38 & 168,146 & $48 \%$ \\
\hline Histopathology ${ }^{4}$ & 75 & 83 & 46 & 74 & 136,557 & $38 \%$ \\
\hline Total Costs & $\$ 193$ & $\$ 168$ & $\$ 118$ & $\$ 128$ & $\$ 352,533$ & $100 \%$ \\
\hline
\end{tabular}


Table 2. Summary of total costs ${ }^{1}$ by lesion management group

\begin{tabular}{|c|c|c|c|c|c|c|}
\hline \multirow[b]{3}{*}{ Management group $^{2}$} & \multirow[b]{3}{*}{ MBS items } & & \multirow{3}{*}{$\begin{array}{l}\text { Mean cost } \\
\text { per lesion } \\
\text { \$Aus }\end{array}$} & \multirow{3}{*}{$\begin{array}{c}\text { Median cost } \\
\text { per lesion } \\
\text { \$Aus }\end{array}$} & \multirow{3}{*}{$\begin{array}{r}\text { Total cost } \\
\text { \$Aus }\end{array}$} & \multirow[b]{3}{*}{$\%$ Total cost } \\
\hline & & No. & & & & \\
\hline & & lesions & & & & \\
\hline \multicolumn{7}{|l|}{ Excisions: } \\
\hline - Melanoma ${ }^{3}$ & $31300-31335$ & $29^{4}$ & 387 & 374 & 11,219 & $3 \%$ \\
\hline$-\mathrm{SCC} / \mathrm{BCC}$ & $31255-31290$ & 329 & 235 & 223 & 77,257 & $22 \%$ \\
\hline - Benign lesions & $31200-31210$ & 893 & 179 & 168 & 159,684 & $45 \%$ \\
\hline Biopsies & 30071 & 139 & 131 & 128 & 18,194 & $5 \%$ \\
\hline Other treatments ${ }^{5}$ & $30192-30205$ & 764 & 81 & 62 & 61,613 & $18 \%$ \\
\hline Referral to specialist & 104 & 40 & 78 & 78 & 3,112 & $1 \%$ \\
\hline No treatment/monitor & $\mathrm{n} / \mathrm{a}$ & 756 & 16 & 16 & 12,126 & $3 \%$ \\
\hline Multiple treatments & multiple & 32 & 292 & 235 & 9,329 & $3 \%$ \\
\hline Total & & 2,982 & $\$ 118$ & $\$ 128$ & $\$ 352,533$ & $100 \%$ \\
\hline
\end{tabular}

1. Includes cost of consultation, diagnosis, management and pathology MBS codes where relevant.

2. Grouped by MBS codes according to similar lesion type or treatment

3. This group of lesion excisions includes Hutchinson's melanotic freckle.

4. This excludes 4 melanomas that required multiple treatment and therefore included in the 'multiple treatments' category.

5. 'Other treatments' includes cryotherapy, topical creams, shave excision, laser phototherapy, curettage, ablation technique. 
Table 3. Summary of $\operatorname{costs}^{1}$ by gender and age group

\begin{tabular}{|c|c|c|c|c|c|c|c|c|}
\hline & $\begin{array}{r}\text { No. } \\
\text { lesions }\end{array}$ & $\begin{array}{l}\text { Mean cost } \\
\text { per lesion } \\
\text { \$Aus }\end{array}$ & $\begin{array}{c}\text { Median cost } \\
\text { per lesion } \\
\text { \$Aus }\end{array}$ & $\begin{array}{c}\text { No. } \\
\text { patients }\end{array}$ & $\begin{array}{c}\text { Mean cost } \\
\text { per patient } \\
\text { \$Aus }\end{array}$ & $\begin{array}{c}\text { Median cost } \\
\text { per patient } \\
\text { \$Aus }\end{array}$ & $\begin{array}{c}\text { Total cost } \\
\text { \$Aus }\end{array}$ & $\begin{array}{c}\% \text { Total } \\
\text { cost }\end{array}$ \\
\hline \multicolumn{9}{|l|}{ Males } \\
\hline$<30$ years & 112 & 132 & 159 & 79 & 187 & 159 & 14,781 & $8 \%$ \\
\hline $30-49$ years & 479 & 114 & 134 & 292 & 187 & 159 & 54,579 & $28 \%$ \\
\hline$\geq 50$ years & 1,024 & 120 & 128 & 587 & 209 & 179 & 122,817 & $64 \%$ \\
\hline Subtotal & 1,615 & 119 & & 958 & 201 & 174 & 192,177 & $55 \%$ \\
\hline \multicolumn{9}{|l|}{ Females } \\
\hline$<30$ years & 98 & 111 & 159 & 74 & 147 & 159 & 10,889 & $7 \%$ \\
\hline $30-49$ years & 429 & 116 & 134 & 284 & 176 & 159 & 49,914 & $31 \%$ \\
\hline$\geq 50$ years & 840 & 119 & 125 & 506 & 197 & 173 & 99,553 & $62 \%$ \\
\hline Subtotal & 1,367 & 117 & & 864 & 186 & 159 & 160,356 & $45 \%$ \\
\hline Total & 2,982 & & & 1,822 & & & $\$ 352,533$ & $100 \%$ \\
\hline
\end{tabular}

1. Includes cost of consultation, diagnosis, management and pathology MBS codes where relevant. 
Table 4. Proportional distribution of total costs ${ }^{1}$ of SkinWatch

referrals (1998-2001) and all Medicare claims ${ }^{2}$ recorded in the intervention and control communities (2001-2002)

\begin{tabular}{|c|c|c|c|}
\hline & $\begin{array}{c}\text { SkinWatch Referrals } \\
(1998-2001) \\
\end{array}$ & $\begin{array}{c}\text { Intervention Communities }^{3} \\
(2001-2002) \\
\end{array}$ & $\begin{array}{c}\text { Control Communities } \\
(2001-2002) \\
\end{array}$ \\
\hline $\begin{array}{l}\text { Management group } \\
\text { (MBS codes) }\end{array}$ & $\%$ & $\%$ & $\%$ \\
\hline $\begin{array}{l}\text { Melanoma excisions } \\
(31300-31335)\end{array}$ & 2.0 & 1.9 & 1.4 \\
\hline $\begin{array}{l}\text { SCC/BCC excisions } \\
(31255-31290)\end{array}$ & 15.8 & 19.3 & 18.8 \\
\hline $\begin{array}{l}\text { Excisions of benign lesions } \\
(31200-31210)\end{array}$ & 26.0 & 28.0 & 27.9 \\
\hline $\begin{array}{l}\text { Biopsies } \\
30071\end{array}$ & 1.8 & 3.4 & 3.2 \\
\hline $\begin{array}{l}\text { Other treatments }^{4} \\
(30192-30205)\end{array}$ & 8.5 & 5.5 & 6.7 \\
\hline $\begin{array}{l}\text { Pathology of skin lesions } \\
(72816-18,72830)\end{array}$ & 46.0 & 41.9 & 42.0 \\
\hline Total & 100 & 100 & 100 \\
\hline Total costs ${ }^{1}$ Aus $\$$ & $\$ 297,058$ & $\$ 1,529,345$ & $\$ 1,123,698$ \\
\hline
\end{tabular}

Costs exclude GP consultation fees and referrals to specialists.

2. Medicare Australia takes care in the compilation and provision of the information and data, it does not assume or accept any liability for the accuracy, quality, suitability and currency of the information or data.

3. This represents population-based claims data on the communities in the trial.

4. 'Other treatments' includes cryotherapy, topical creams, shave excision, laser phototherapy, curettage, ablation technique. 
Acronym list

BCC Basal cell carcinoma

SCC Squamous cell carcinoma

NMSC Non-melanoma skin cancer

MBS Medicare Benefit Schedule

US United States 